\title{
Diamond formation through mineral hydration at the base of the transition zone
}

\author{
DANIEL FROST ${ }^{1}$, RONG HUANG ${ }^{2}$, CATHERINE $^{2}$ \\ MCCAMMON $^{1}$ AND TIZIANA BOFFA BALLARAN ${ }^{1}$ \\ ${ }^{1}$ University of Bayreuth \\ ${ }^{2}$ Bayerisches Geoinstitut \\ Presenting Author: dan.frost@uni-bayreuth.de
}

Beneath the $660 \mathrm{~km}$ seismic discontinuity low seismic wave velocities have been proposed based on observations of P-to-S conversions. This could be interpreted as arising from melt layers formed through dehydration as material is transported downwards out of the mantle transition zone. This would be consistent with a decrease in the amount of water that can be stored in mineral structures as material leaves the transition zone. However, the composition, and particularly the iron content, of such a melt layer is still poorly constrained, although important for estimating the likely melt density and therefore buoyancy.

We have investigated ferrous and ferric iron partitioning between bridgmanite ( $\mathrm{Brg}$ ), ferropericlase (FP) and coexisting hydrous melt at $25 \mathrm{GPa}$ and $1973 \mathrm{~K}$. Hydrous ultramafic starting materials were employed and by placing $\mathrm{Ir}$ metal in the experiments an $f_{\mathrm{O}_{2}}$ of iron wüstite (IW) +2 was obtained. The molar $\mathrm{Fe} /(\mathrm{Mg}+\mathrm{Fe})$ ratios of the melts are approximately 0.35 , which is twice more than the ratio of coexisting Brg but lower than Fp. Hydrous partial melts produced at the top of the lower mantle at temperatures $<2000 \mathrm{~K}$ are $\mathrm{FeO}$ and $\mathrm{MgO}$-rich with a $(\mathrm{Mg}+\mathrm{Fe}) / \mathrm{Si}$ ratio $>2.5$. Although the melt is iron rich, the estimated melt density is much lower than the density of the surrounding lower mantle, even when large uncertainties on the water content are assumed.

We argue that such melts would rise out of the lower mantle but gradually crystalize in the transition zone as they lose water to surrounding ringwoodite. Although water would be the predominant melt volatile component, carbon would inevitably be present and at plausible mantle oxygen fugacities diamond growth from the melts would occur as they crystalize. The high $\mathrm{FeO}$ and $\mathrm{MgO}$ contents of the melts can explain the range of ferropericlase compositions found as inclusions in diamonds and the scenario is also consistent with the discovery of a near water saturated ringwoodite inclusion (Pearson et al., 2014).

Pearson, D., Brenker, F., Nestola, F. et al. Hydrous mantle transition zone indicated by ringwoodite included within diamond. Nature 507, 221-224 (2014). https://doi.org/10.1038/nature13080 